\title{
Investigation on the material removal and surface roughness in ultraprecision machining of $\mathrm{Al} / \mathrm{B}_{4} \mathrm{C} / 50 \mathrm{p}$ metal matrix composites
}

\author{
Zhichao Niu $^{1} \cdot$ Kai Cheng ${ }^{1}$
}

Received: 22 May 2019 / Accepted: 2 October 2019/Published online: 8 November 2019

(C) The Author(s) 2019

\begin{abstract}
Metal matrix composites (MMCs) are increasingly applied in various engineering industries because of their distinct physical and mechanical properties. While the precision machining of MMCs is less understood due to their complex microstructure and poor machinability, a comprehensive scientific understanding on their machining mechanics and the associated surface generation mechanisms is of great importance particularly for industrial scale applications of MMCs. This paper presents a simulation and experimental-based holistic investigation on cutting mechanics, material removal and surface roughness in ultraprecision machining of MMCs. $\mathrm{B}_{4} \mathrm{C} / \mathrm{Al} 2024$ is selected as the targeted MMC material in this research. The thermal-mechanical-tribological integrated modelling and analysis are presented to investigate the effects of cutting speed, feed rate and depth of cut (DOC) on the material removal, chip formation mechanics and surface generation process. The simulation results indicate that the machined surface roughness in precision machining of particle reinforced MMCs can be reduced by increasing the cutting speed and decreasing the depth of cut. The surface flow waviness decreases, which contributes to a higher surface quality, while machining with a smaller feed rate. The well-designed machining trials are conducted under the same cutting conditions and process variables as those in simulations, which perform a good agreement with simulation results.
\end{abstract}

Keywords Metal matrix composites $\cdot$ Cutting mechanics $\cdot$ Material removal $\cdot$ Chip formation $\cdot$ Surface roughness $\cdot$ Ultraprecision machining

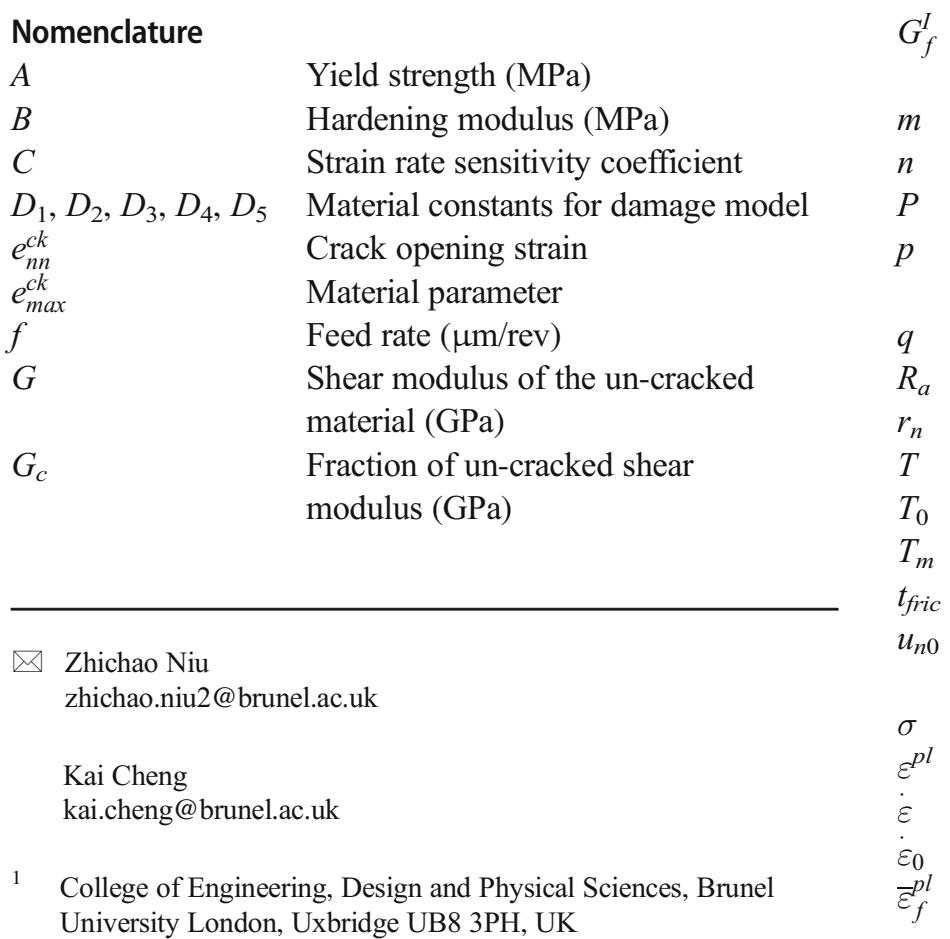

Energy required for opening a unit area of crack $\left(\mathrm{J} / \mathrm{m}^{2}\right)$

Thermal softening exponent

Strain hardening exponent

Material parameter

Pressure stress effective cutting

stress (MPa)

Effective cutting stress (MPa)

Surface roughness (nm)

Nose radius $(\mu \mathrm{m})$

Current cutting temperature $\left({ }^{\circ} \mathrm{C}\right)$

Room temperature $\left({ }^{\circ} \mathrm{C}\right)$

Melting temperature $\left({ }^{\circ} \mathrm{C}\right)$

Friction $(\mathrm{N})$

Crack normal displacement at the

failure point $(\mu \mathrm{m})$

Material flow stress (MPa)

Effective plastic strain

Equivalent plastic strain rate $\left(\mathrm{s}^{-1}\right)$

Reference strain rate $\left(\mathrm{s}^{-1}\right)$

Strain at material failure 


$\begin{array}{ll}\omega & \text { Damage parameter } \\ \sigma_{t u}^{I} & \text { Mode I fracture energy (MPa) } \\ \mu & \text { Friction coefficient } \\ \delta_{n} & \text { Normal pressure (MPa) } \\ \delta_{y} & \text { Material initial yield stress (MPa) } \\ \tau_{s} & \text { Limit shear stress (MPa) }\end{array}$

\section{Introduction}

Metal matrix composites are highly competitive compared with conventional materials for many engineering applications due to their outstanding performance including light weight, high strength, high stiffness, low thermal expansion and good wear resistance [1]. Considering these properties, particle reinforced MMCs such as $\mathrm{B}_{4} \mathrm{C} / \mathrm{Al}$ MMC have been extensively applied in various engineering industries such as aerospace, military defence and nuclear industries, etc. [2]. In addition, $\mathrm{B}_{4} \mathrm{C} / \mathrm{Al} \mathrm{MMC}$ can be designed in light of the material requirements for high precision engineering and proposed as the alternative in specific engineering applications [3]. However, the typical inhomogeneity, anisotropy and low ductility of such MMCs lead to their hard-to-machine and high costs in manufacturing [4]. Rapid tool wear, higher energy requirement, and the associated poor machinability and surface integrity are potential drawbacks of precision machining MMCs, which are hindering their industrial scale applications $[5,6]$.

Therefore, scientific understanding and comprehensive analysis on the material deformation behaviour, the effects of reinforcements on the chip formation and the MMC's machinability are essentially critical for achieving higher surface integrity, extending tool life, further minimizing machining cost and extending the MMCs into high-volume industrial scale applications. Machining process variables, particularly for cutting speed, feed rate and depth of cut, significantly affect the material removal process, and thereby the surface roughness and material machinability. These have similar effects on surface finish in machining metal matrix composites to those of machining homogeneous materials. However, some differences are noticeable due to the existence of reinforced particles oriented microstructure at MMCs [7]. Substantial finite element (FE) modelling and analysis on MMCs machining have been carried out, especially on the cutting mechanics and machining processes for MMCs. Pramanik et al. [8] introduced MMCs machining characteristics by categorizing the tool-particle interaction into three scenarios: particles along, above and below the cutting path. The FE-based simulation indicates tool-particle interaction and stress/strain distributions in the particles/matrix are responsible for particle de-bonding, surface damage and tool wear significantly. Zhou et al. [9] studied the cutting process of $\mathrm{SiCp} / \mathrm{Al}$ composites by using cutting force and von Mises equivalent stress models at different cutting conditions. The
FE simulation results presented indicate that the cutting speed and depth of cut have significant effects on the cutting force and stress distributions on both particle and matrix. An enhanced FEM model, used for characterizing the particle sizedependent flow strengthening and MMCs interface damage by considering incorporated direct strengthening, indirect strengthening and interfacial de-bonding effects, has been developed by Shao et al. [10]. Ghandehariun et al. [11] proposed a FE model to study de-bonding and fracture of reinforced particles at different cutting scenarios. The MMC machining process and the associated surface roughness, subsurface damage and tool wear have been extensively studied experimentally as well. The optimal machining conditions for particle reinforced MMCs have been the topic of most research recently [12-14]. Manna and Bhattacharyya [15] proposed a Taguchi method-based approach in investigating MMCs turning processes which indicates the influence of cutting speed, feed and depth of cut is more or less equal to that on the surface roughness $(\mathrm{Ra})$; depth of cut and feed have more influence on the maximum peak-to-valley roughness height (Rt) comparing to the cutting speed. Wang et al. [16] developed an experimental research on high speed milling of $\mathrm{Al} / \mathrm{SiC} / 65 \mathrm{p}$, which revealed that the most significant cutting parameter for surface roughness is milling speed, followed by the interaction between feed rate and milling speed, then the feed rate. Babu et al. [17] found that feed rate is the dominate parameter that affect the surface roughness followed by cutting speed in turning $\mathrm{Al} / \mathrm{SiC} / \mathrm{B}_{4} \mathrm{C}$ MMCs, while DOC shows the minimal effect on surface quality. The presence of $\mathrm{B}_{4} \mathrm{C}$ particles at the matrix has contributed significantly on increasing surface roughness (Ra) and cutting speed contributes more than other variables on affecting the surface roughness as found by Kumaran [18]. For the particle effects, the amount of cracks and pits are found significantly reduced in machining with high cutting speed in turning $15 \% \mathrm{SiCp} / \mathrm{Al}$ [19]. Although the investigation on MMCs machining processes has been extensively developed [20], most research and development work are focused on an individual application case study, a holistic scientific understanding of the machining process is becoming essentially important. Furthermore, the cutting mechanics particular for the chip formation process and surface generation are still less understood. In addition, the role that these reinforced particles play during chip formation and the way in which the particles are removed or fractured are also absent, which can be very useful data and information for the materials design and fabrication particularly towards having much improved machinability performance.

This paper presents a holistic simulation-experiment integrated approach to investigating the effects of cutting parameters, particular for cutting speed, feed rate and depth of cut, on material removal and surface roughness in ultraprecision machining of MMCs, and the consequent scientific understanding of the machining mechanics. The findings are 
essential for developing the machining process optimization strategy. The effects of reinforced particles at the MMCs on the machined surfaces are also presented including the chip formation, surface generation and surface defects in the machining process.

\section{Integrated modelling and analysis of MMCs machining}

The modelling and analysis below are conducted through a thermal-mechanical-tribological integrated approach under the multiphysics modelling and analysis thinking. The finite element analysis of MMCs microcutting mechanisms particularly for chip formation mechanics are carried out in Abaqus/Explicit 6.14. The schematic of this $2 \mathrm{D}$ orthogonal microcutting model is illustrated in Fig. 1. In terms of the MMCs workpiece, $\mathrm{B}_{4} \mathrm{C}$ particles with a volume fraction of $50 \%$ are found evenly distributed in $\mathrm{Al} 2024$ matrix due to fabrication method. The average grain size of $\mathrm{B}_{4} \mathrm{C}$ particles is $5 \mu \mathrm{m}$ in diameter. According to the powder metallurgy fabrication method, mechanical bonding is found on the interface between matrix material and particle. Thus, particles are only simulated by tied together with the matrix material which enables their initial displacements at the interface area are both equal to zero rather than constructing an artificial layer in interface when modelling interface properties. The interfacial de-bonding can be achieved through matrix material failure [21]. The MMCs cutting behaviour is significantly affected by the cutting parameters and the location of particles relative to the position of cutting tool. Thus, models are conducted under various cutting parameters and particle positions relative to the cutting tool. Polycrystalline diamond (PCD) tools, which offer higher tool life due to their high hardness and thermal conductivity, are normally used in MMCs machining $[22,23]$. Therefore, a PCD tool with the rake angle and the relief angle defined as $-5^{\circ}$ and $5^{\circ}$ respectively is applied in this model. The PCD tool can be configured as a rigid body in the whole cutting process due to its extremely high strength, while heat transfer on the cutting tool is still active. The edge radius of cutting tool tip is $3.5 \mu \mathrm{m}$. Free mesh with quadrilateral continuum elements CPE4RT units and triangle elements CPE3T units are used to model the MMCs workpiece and PCD tool, respectively. The FE simulation is conducted under a fully coupled dynamic, tempdisp, explicit multiphysics condition. In this model, left and bottom sides of the workpiece are constrained on the movement in each direction and rotation, while the cutting tool moves towards the workpiece with a defined velocity. A reference point is defined on the cutting tool in order to control the boundary conditions and achieve the simulation results. The simulations are carried out under various cutting speed, feed rate and depth of cut. The cutting speed of $157.0 \mathrm{~m} / \mathrm{min} / 125.7 \mathrm{~m} / \mathrm{min} / 94.2 \mathrm{~m} / \mathrm{min}$, feed rate of $10 \mu \mathrm{m} / \mathrm{rev} / 20 \mu \mathrm{m} / \mathrm{rev} / 30 \mu \mathrm{m} / \mathrm{rev}$ and DOC of $1 \mu \mathrm{m} /$ $2.5 \mu \mathrm{m} / 4 \mu \mathrm{m}$ are selected and performed in the simulation processes and further used in the machining trials.

\subsection{Material constitutive model}

(1) Matrix material: As the Al 2024 matrix is a typical elastic-plastic material, Johnson-Cook model is applied. Thus, the material flow stress $\sigma$ can be represented by the following equation [24]:

$\sigma=\left[A+B\left(\varepsilon^{p l}\right)^{n}\right]\left(1+C \ln \frac{\dot{\varepsilon}}{\dot{\varepsilon}_{0}}\right)\left[1-\left(\frac{T-T_{0}}{T_{m}-T_{0}}\right)^{m}\right]$

where $\varepsilon^{p l}$ is the effective plastic strain, $\dot{\varepsilon}$ is the equivalent plastic strain rate and $\dot{\varepsilon}_{0}$ is the reference strain rate. $T, T_{0}$ and $T_{m}$ are the current cutting temperature, room temperature and melting temperature of material, respectively. $A, B, C, n$ and $m$ are the material model parameters measured at or below the
Fig. 1 Finite element model for MMCs precision machining

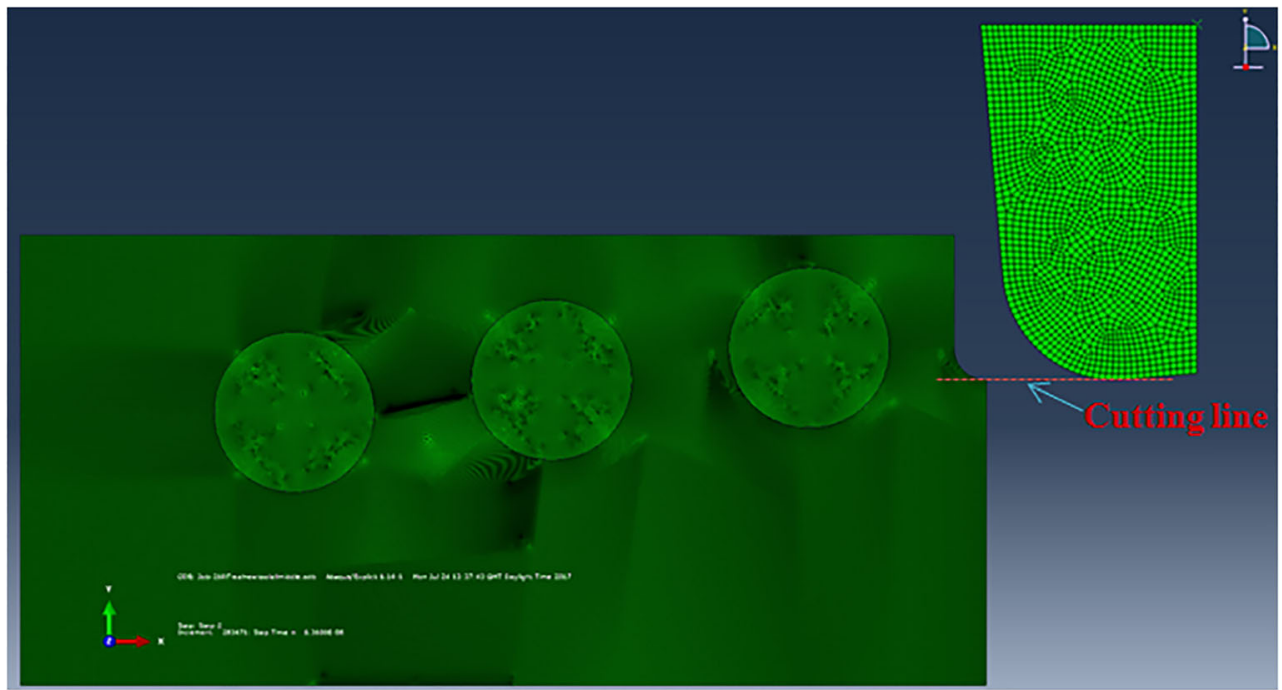


transition temperature. $n$ is the strain hardening exponent and $m$ is the thermal softening exponent. The physical properties of matrix material, particles and PCD tool used in the simulation and material constants are shown in Tables 1 and 2, respectively. Johnson-Cook dynamic failure model, which is recommended as the critical technique for modelling the cutting progressive damage and the material failure, is applied in this model. The damage of matrix material is expressed by equation [22]:

$\frac{p l}{\bar{\varepsilon}_{f}}=\left[D_{1}+D_{2} \exp \left(D_{3} \frac{p}{q}\right)\right]\left[1+D_{4} \ln \left(\frac{\dot{\varepsilon}}{\dot{\varepsilon}_{0}}\right)\right]\left(1+D_{5} \frac{T-T_{0}}{T_{m}-T_{0}}\right)$

where $\bar{\varepsilon}_{f}^{p l}$ is the strain at material failure, $D_{1} \sim D_{5}$ are the material constants for damage model, $\frac{p}{q}$ is a dimensionless pressure-deviatoric stress ratio, where, $p$ is the pressure stress and $q$ is the Mises stress which represents the effective cutting stress, $\frac{\varepsilon}{\varepsilon_{0}}$ is the nondimensional plastic strain rate. Table 3 shows the material constants for this damage model. A linear evolution of damage variable is assumed for the damage model. Based on the value of the equivalent plastic strain at element integration points, the damage parameter $\omega$ can be defined as $\omega=\sum\left(\frac{\Delta \bar{\varepsilon}^{p l}}{\bar{\varepsilon}_{f}^{p l}}\right)$. Where, $\Delta \bar{\varepsilon}^{p l}$ is the change of equivalent plastic strain in each integration cycle. Thus, the material stiffness will be fully degraded and material failure occurs when the damage parameter $\omega$ exceeds 1 .

(2) Reinforced particles: Due to the brittle properties of $\mathrm{B}_{4} \mathrm{C}$, particles are observed as perfectly elastic material until failure. A brittle cracking model is used to present the fracture of particles. In this model, the crack normal displacement at the failure point can be determined as

$u_{n 0}=\frac{2 G_{f}^{I}}{\sigma_{t u}^{I}}$

where $G_{f}^{I}$ is expressed as energy required for opening a unit area of crack, $\sigma_{t u}^{I}$ is defined as a tabular function of the associated mode I fracture energy. In addition, the post-cracking shear modulus $G_{c}$ in brittle shear model is defined as a fraction of un-cracked shear modulus as shown in Eq. (4).
Table 2 Material constants for Johnson-Cook plasticity model [26]

\begin{tabular}{llllllll}
\hline Material & $A$ & $B$ & $C$ & $n$ & $m$ & $T_{m}$ & $T_{0}$ \\
\hline $\mathrm{Al} 2024$ & $369 \mathrm{MPa}$ & $684 \mathrm{MPa}$ & $8.3 \mathrm{e}-3$ & 0.73 & 1.7 & $502{ }^{\circ} \mathrm{C}$ & $20^{\circ} \mathrm{C}$
\end{tabular}

$G_{c}=\left(1-\frac{e_{n n}^{c k}}{e_{\max }^{c k}}\right)^{p} G$

where $G$ is shear modulus of the un-cracked material; $e_{n n}^{c k}$ is crack opening strain; $e_{\max }^{c k}$ and $P$ are material parameters [24]. Material parameters for brittle cracking model are shown in Table 4.

\subsection{Tool-workpiece interaction and heat generation}

The interaction of tool/matrix material and tool/particles are simulated through kinematic surface-to-surface contact pair model. The friction model $t_{\text {fric }}=\min \left(\mu \delta_{n}, \tau_{s}\right)$ is applied, where $\mu$ is the friction coefficient that defined as a function of contact pressure; $\delta_{n}$ is the normal pressure on the chip and cutting tool interface; $\tau_{s}$ is the limit shear stress which can be calculated from the equation expressed as $\tau_{s}=\delta_{y} / \sqrt{3} . \delta_{y}$ is the material initial yield stress. The contact pairs, which are controlled by Coulomb friction law [27], are given a constant friction coefficient of 0.35 [28].

In MMCs ultraprecision machining, a thermal module is applied and integrated in the FE model due to most energy consumption in chip formation progress including the chip generation and chip sliding on tool surface are finally convert to the thermal energy. The dissipated energy generated by material plastic deformation and tool-workpiece friction is almost performed as heat source afterwards. The heat generation and heat transfer on the tool/workpiece contact area result in the material soften, tool wear occurrence and tool failure. In addition, the cutting stress and cutting force change significantly under varied heat.

\section{Simulation results, analysis and discussion}

\subsection{Chip formation mechanisms}

The chip formation process including matrix material elastic/ plastic deformation, reinforced particles de-bonding/
Table 1 Properties of workpiece and cutting tools $[9,25]$

\begin{tabular}{llll}
\hline Material & Matrix: Al 2024 & Particles: $\mathrm{B}_{4} \mathrm{C}$ & Tool: PCD \\
\hline Thermal conductivity $(\mathrm{W} /(\mathrm{mK}))$ & 190 & 42 & 2100 \\
Density $\left(\mathrm{g} / \mathrm{cm}^{3}\right)$ & 2.77 & 2.52 & 4.25 \\
Elasticity modulus $(\mathrm{GPa})$ & 73 & 460 & 1147 \\
Poisson's ratio, $\nu$ & 0.33 & 0.19 & 0.07 \\
Specific heat $(\mathrm{J} /(\mathrm{kgK}))$ & 875 & 945 & 525 \\
\hline
\end{tabular}


Table 3 Material constants for Johnson-Cook damage model [26]

\begin{tabular}{llllll}
\hline Material & $D_{1}$ & $D_{2}$ & $D_{3}$ & $D_{4}$ & $D_{5}$ \\
\hline Al 2024 & 0.112 & 0.123 & 1.5 & 0.007 & 0 \\
\hline
\end{tabular}

dislocation/fracture and reaction on matrix/particle interfacial bonding area in ultraprecision machining of MMCs are complex. The fracture orientations, which determine the chip formation properties and the resultant surface quality, are varied under different cutting conditions. Thus, an in-depth understanding of chip formation mechanics in order to achieve better surface roughness and surface performance is of great importance. The interaction between tool cutting edge and workpiece including matrix material, particles and their interface is involved in the simulations. Three cutting scenarios, which are defined as particle centre is located higher than the cutting line, particle centre is located on the cutting line and particle centre is located lower than the cutting line, are investigated, respectively.

For the scenario of the particle centre is located higher than the cutting line, the cutting tool firstly approaches into the matrix material. Plastic and elastic deformation on the matrix material occurs and it can be observed that chips generated along the cutting line. With the continued approach of the cutting tool, dramatically increased stress results in a high strain on the matrix/particle interface.

When the cutting force exceeds the bonding force, bonding failure occurs on the interfacial boundary. Meanwhile, some small voids are formed along the separation direction of matrix/particle pairs due to the stress concentration at the interface. The crack propagation is enhanced through the coalescence of these voids that can be observed in Fig. 2b. Matrix material breakage significantly occurs and chips formed on the shearing plane with the further approach of cutting tool. When the tool attaches on the reinforced particle, the high stress leads to the fracture of brittle particle and a groove leaves on the particle at first. With the continue fracture of particle, cracks are generated towards both upper and lower directions of un-machined particle area shown in Fig. 2d. As the tool keeps moving forward, more cracks are found and discontinued chips of matrix material can be observed in Fig. 2e. The cavity, particularly on the particle/matrix interfacial area, can be found after the tool cuts through the whole surface. In addition, more cracks occur at the approach in side of fractured particles. This occurs due to the suddenly

Table 4 Material parameters for brittle cracking model [25]

\begin{tabular}{lllll}
\hline Material & $\sigma_{t u}^{I}(\mathrm{MPa})$ & $p$ & $G_{f}^{I}\left(\mathrm{~J} / \mathrm{m}^{2}\right)$ & $e_{\max }^{c k}$ \\
\hline $\mathrm{B}_{4} \mathrm{C}$ & 155 & 1 & 50 & 0.001 \\
\hline
\end{tabular}

increased stress on the interface results in the crack propagation enhanced dramatically.

For the scenario of the particle centre is located lower than the cutting line, the matrix material breakage is similar as the particle centre is located higher than the cutting line. Interfacial de-bonding and matrix breakage occur significantly. While, the fracture properties of particle have difference. When the tool attaches on the particle, the high stress leads to the fracture of brittle material and further approach of cutting tool results in almost all of the cracks generated towards lower direction of un-machined particle area as shown in Fig. 3a. As the tool keeps moving forward, more cracks are found as well. The cavity, particularly on the particle/matrix interfacial area, can be found after the tool cuts through the whole surface. While, more cracks can be observed at the tool approach out area of fractured particle. This can be attributed to the particle has been fractured before the tool approach out and these fractured elements go along with the formed matrix material chips afterwards.

For the scenario of the particle centre is located on the cutting line, the matrix material breakage is still similar as those in the other two scenarios. The particle fracture properties are interesting that the high stress leads to the fracture of brittle material when first attach and with further approach of cutting tool, the cracks generated towards the cutting direction of un-machined particle area as shown in Fig. 4a. This indicates that the particles break along the cutting line with fewer cracks formed along the tool path and finally leaves a much smoother surface when cutting on the cutting line.

Due to the extremely high shear stress, the primary chipforming mechanism involves the initiation of cracks from the free surface of the chips. The normal distribution of reinforced particles and their high-volume fraction result in the discontinued chip formation. The average chip lengths shown in these three scenarios are similar which are around $5 \mu \mathrm{m}$. The particles with brittle properties are performed by small segments that link to each other. These segments are separated during the cutting process and chips are observed as small segments in the end. Some of these segments may fill the cracks during the machining and make the resultant surface smoother, while most of them are removed along with the chips. Thus, the chip formation in MMCs ultraprecision machining can be seen as powder form chips according to the properties of matrix material breakage and particle fracture as shown in the integrated simulation results.

\subsection{Surface generation and surface roughness}

Along with the interaction of tool/matrix and tool/particle pairs, surface generated gradually. Material fracture and surface defects occur along the feed direction and cutting direction. Thus, cutting speed, depth of cut and feed rate are 
Fig. 2 Scenario of the particle centre is located higher than the cutting line

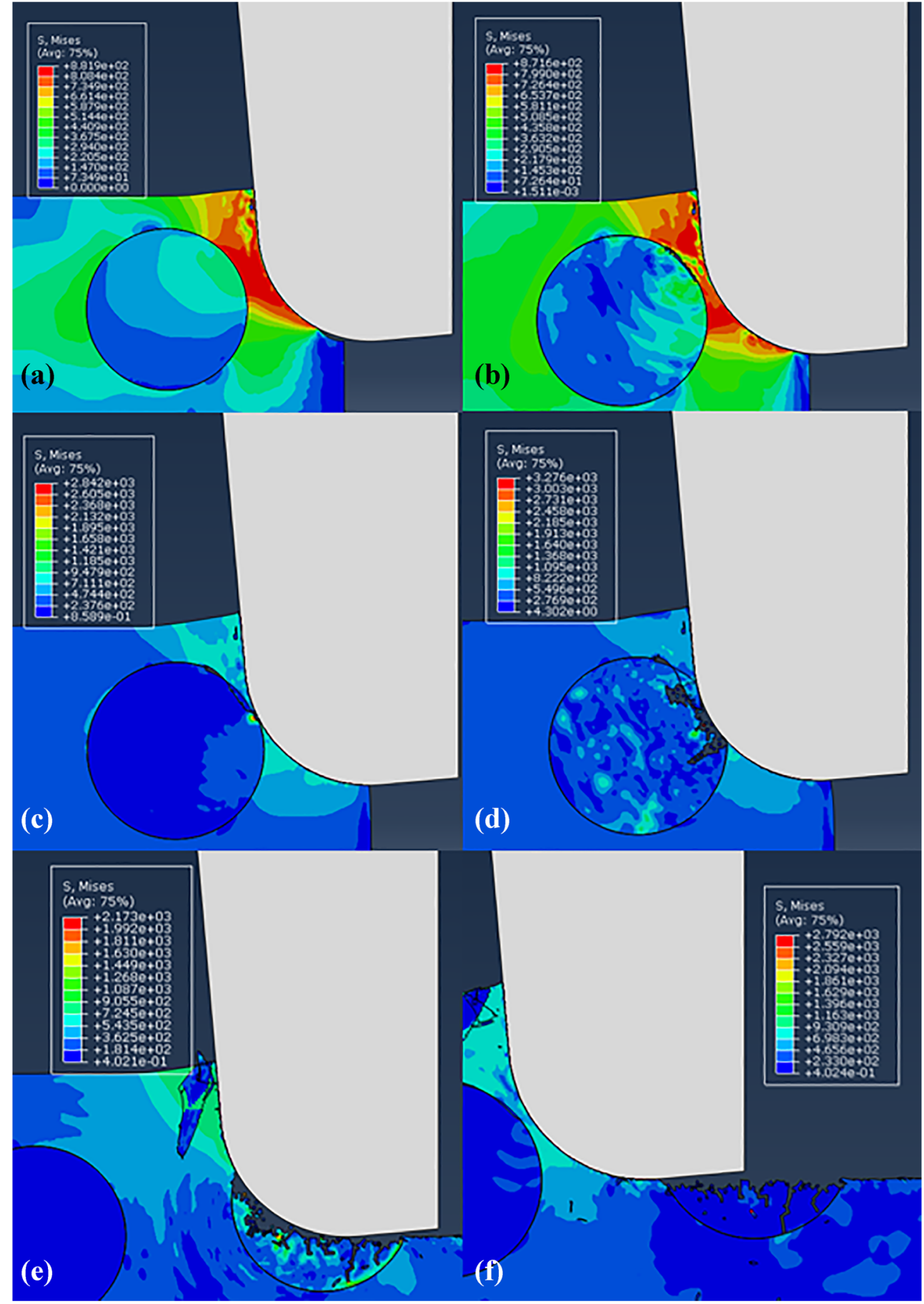

considered as the critical factors in the MMCs ultraprecision machining simulations.

(1) Influence of cutting speed: From Fig. 5, it can be observed that machined surface defects reduce and surface quality increases with the increase of cutting speed. In this situation, with the increase of cutting speed, the strain rate presents a linear increase. According to the
Johnson-Cook damage model, it is known that the strain at material damage is a function of dimensionless pressure-deviatoric stress ratio, non-dimensional plastic strain rate and cutting temperature. While considering the constants for the damage model (Eq. 2) showed in Table 2, the matrix material failure strain $\bar{\varepsilon}_{f}^{p l}$ is strongly dependent on the stress ratio and has the extremely low dependence on strain rate $\frac{p}{q}$ and temperature $T$. Thus, the 
Fig. 3 Scenario of the particle centre is located lower than the cutting line

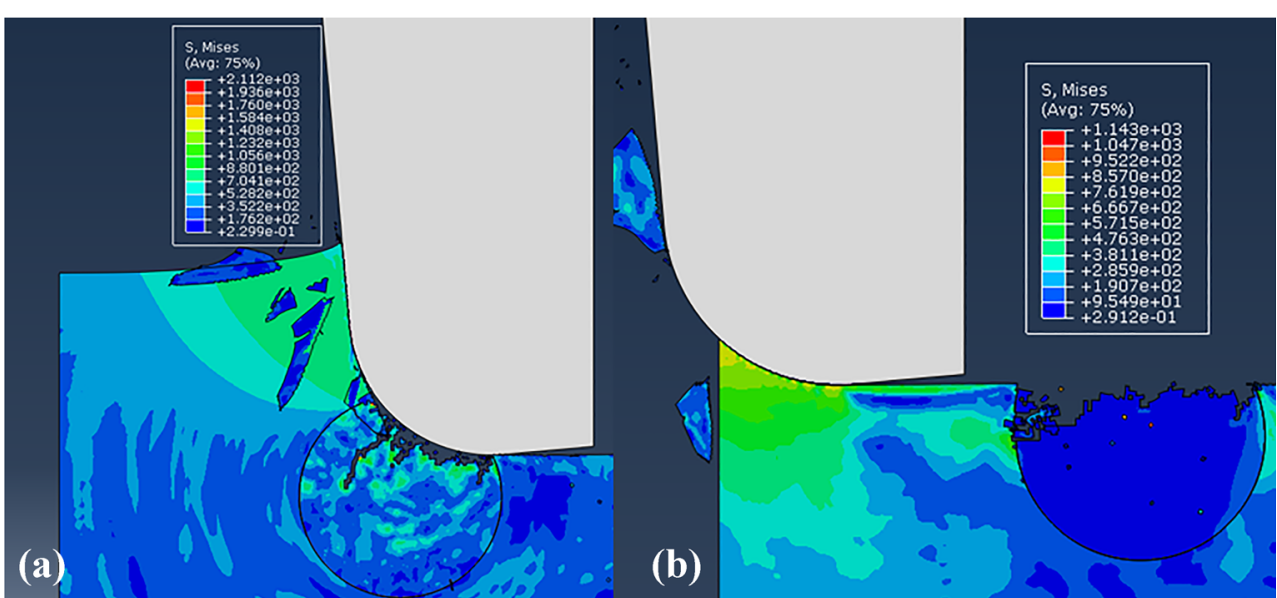

damage strain decreases with the increase of Mises stress. In addition, matrix material is easier to be removed and plastic deformation of the machined surface is reduced which leads to a smooth surface generation. Figure 6 shows the cutting stress on the MMCs cutting region vs time point at varied cutting speed. Figure 7 further shows the stress value on matrix material and reinforced particles. According to the stress curve, it can be found that machined surface roughness is smaller and surface quality is higher when machining with a higher cutting speed. Moreover, the larger strain rate results in the larger yield strength and failure stress, which means the material on the remained surface is more difficult to be removed. Thus, the stress acts on the matrix material increases when the cutting speed increases. As a result, the stresses that transfer to the bonding interface and uncut particles are larger as well. For the brittle particles, the stress does not state significant difference at varied cutting speed. This indicates that particles are fractured with similar cracks generated. However, when machining with higher cutting speed, the tool-particle interaction time reduces. The cracks on the machined surface thus have less time to transfer or further progress leading into larger cavities. Conversely, the particle deformation failure strain is larger which leads to more time for cracks growing when machining with a low cutting speed. The generated cracks extend and further link together into big cavities. Thus, machined surface quality is higher under higher cutting speed condition.

(2) Influence of depth of cut: Due to the normal distribution of particles, the particle locations on each cutting line are almost the same. Thus, the interaction and the attach area between tool and particles can be seen as the same on each cutting line. In addition, the estimated minimum chip thickness (MCT) [29] is $0.525 \mu \mathrm{m}$ in this case. Thus, chips can be formed under the selected depth of cut. The influence of depth of cut on the machined surface performance in this simulation is shown in Fig. 8.

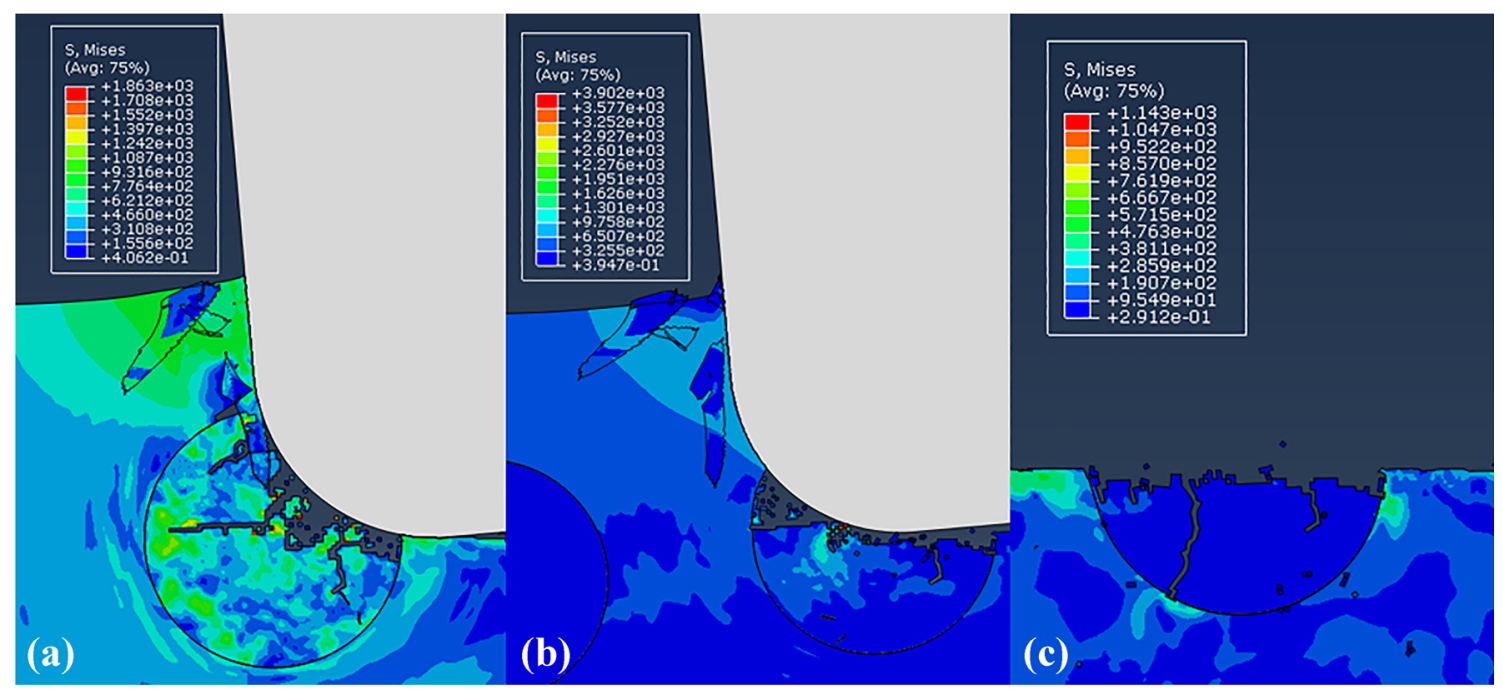

Fig. 4 Scenario of the particle centre is located on the cutting line 
Fig. 5 Surface performances at varied cutting speeds. a Cutting speed $157.0 \mathrm{~m} / \mathrm{min}$. b Cutting speed $125.7 \mathrm{~m} / \mathrm{min}$. c Cutting speed $94.2 \mathrm{~m} / \mathrm{min}$

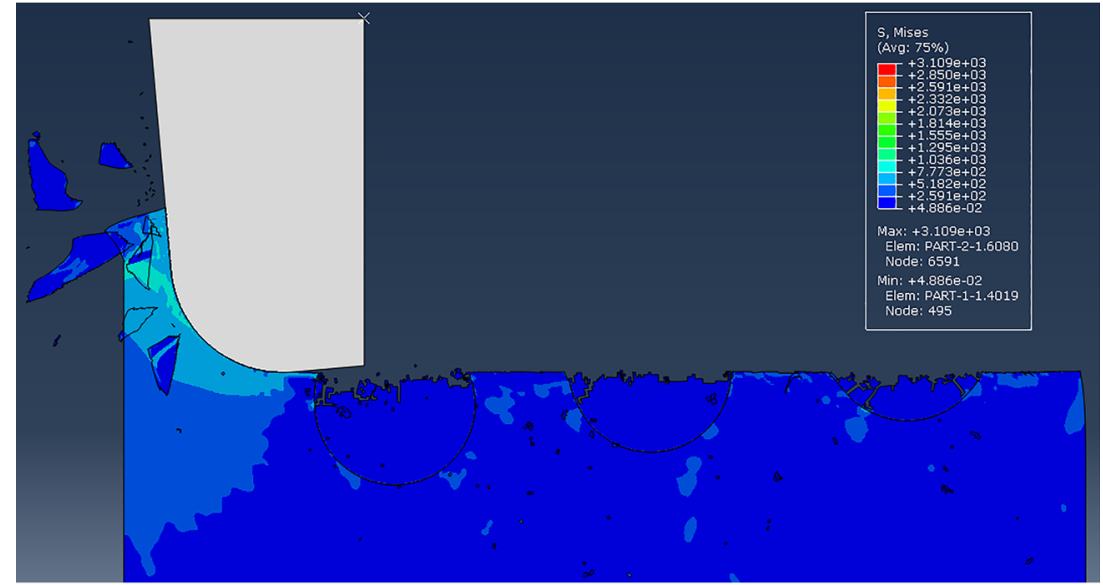

(a) Cutting speed: $157.0 \mathrm{~m} / \mathrm{min}$

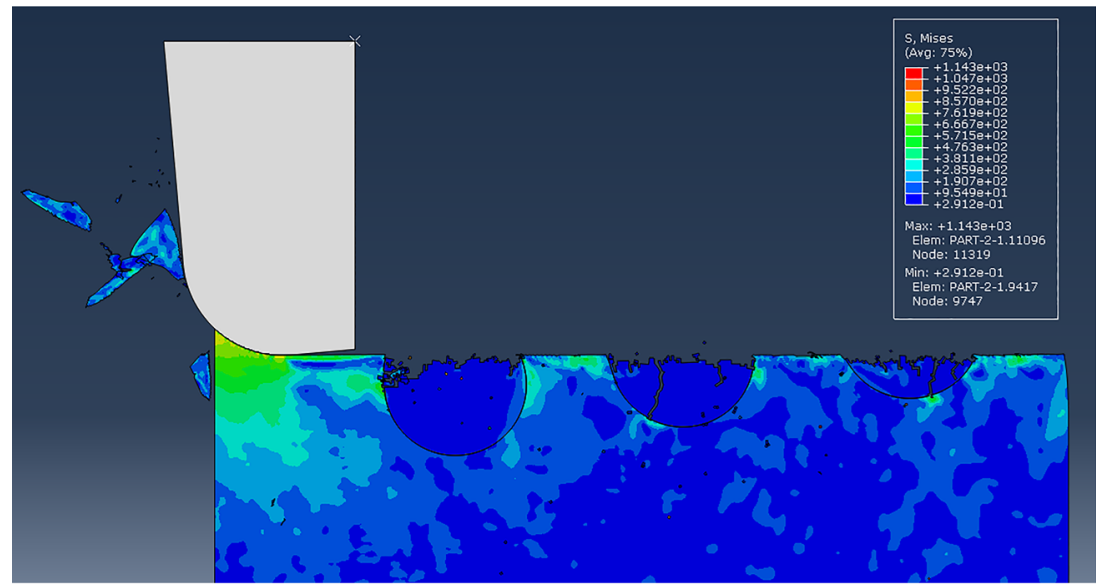

(b) Cutting speed: $125.7 \mathrm{~m} / \mathrm{min}$

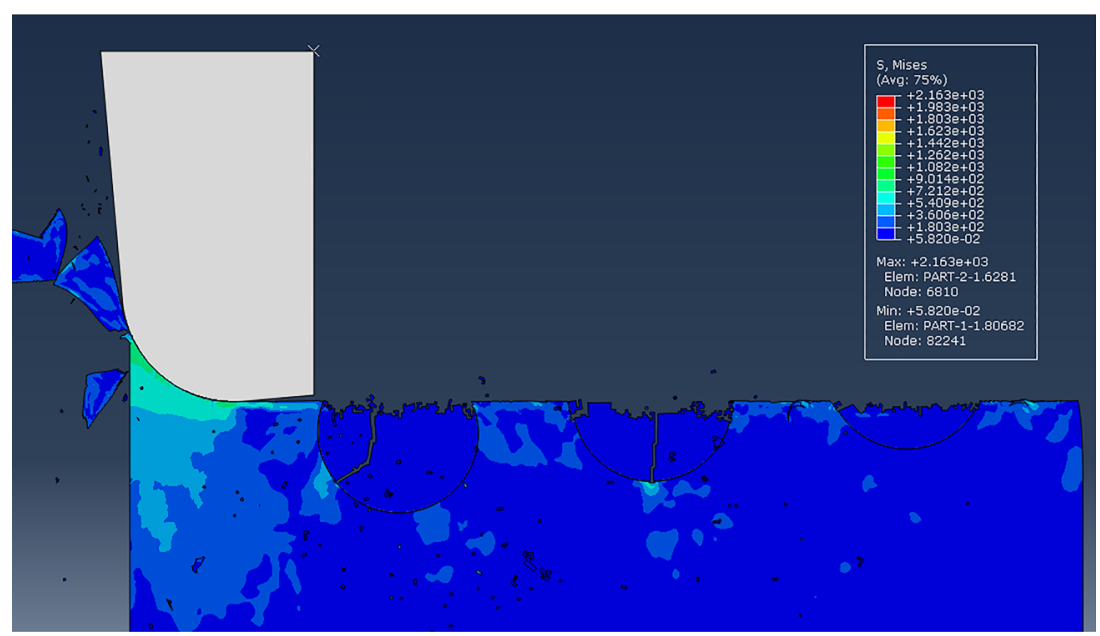

(c) Cutting speed: $94.2 \mathrm{~m} / \mathrm{min}$
From the simulation results, it can be observed that surface roughness is not significantly affected by the DOC.
Only slightly increase on surface roughness occurs when machining with larger DOC. Thus, the DOC is not 


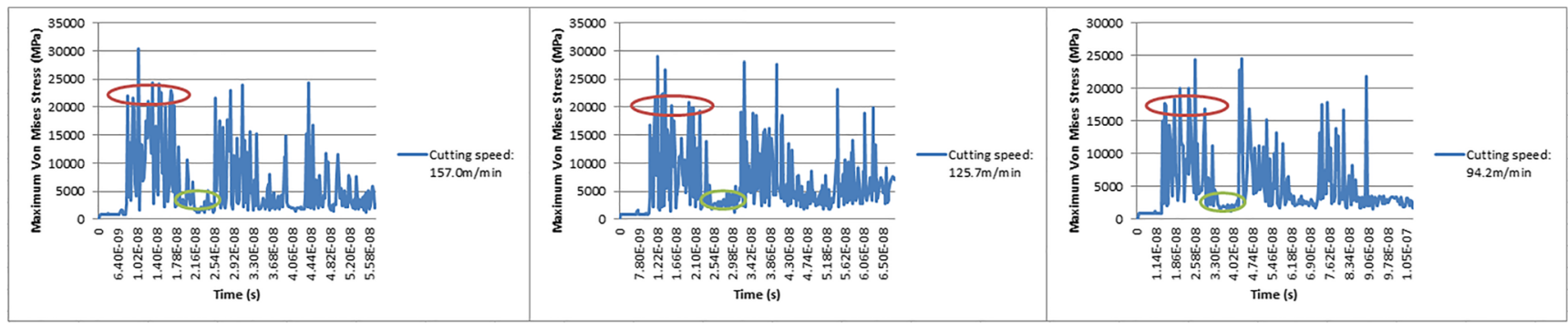

Fig. 6 Cutting stress at varied cutting speeds (green: matrix material breakage; red: particle fracture)

dominating to the surface performance, while a better surface quality can be obtained by reducing the DOC in MMCs ultraprecision machining.

(3) Influence of feed rate: The effect of feed rate on surface generation is also critical in MMCs ultraprecision machining, while this cannot be achieved in 2D simulation progress. Thus, the generated surface along feed rate direction in real cutting process can be predicted by using Matlab. The surface profiles are simulated by considering the cutting tool path and tool position in each cutting cycle. Average surface roughness $R_{a}$ can be predicted through equation: $R_{a}=f^{2}$ / $31.2 r_{n}$ [30]. Figure 9 illustrates the simulated surface profiles under varied feed rate. The resultant peak-tovalley value and roughness of machined surfaces are shown in Table 5. Form the simulation results, it can be observed that the surface roughness value increases with the increase of feed rate. Due to the existence of cutting tool nose radius, the generated tool marks are much more significant which leaves larger peaks on the remained surface when machining with larger feed rate. Machining under a smaller feed rate, which is still larger than minimum chip thickness, is reasonable in MMCs microturning process in order to reduce the surface roughness and form surface with a higher quality.
From the multiphysics-based integrated modelling and analysis and simulation results, it can be found that cutting speed, feed rate and DOC are the dominate cutting parameters having significant effects on chip formation, material removal and the machined surface roughness in MMCs ultraprecision machining processes. Considering the most prominent factors, matrix material breakage, particle fracture and surface generation are varied under different cutting conditions. The simulation results indicate that surface roughness can be reduced and surface quality can be enhanced under a proper lower feed rate, smaller depth of cut and a higher cutting speed in MMCs microturning process. These are further evaluated and validated through well-designed experiments shown as below.

\section{Experimental evaluation and validation}

\subsection{Experimental set-up}

A series of machining trials for evaluating and validating the simulation results are carried out on MOORE Nanotech 250 UPL ultra-precision turning machine. The schematic of PCD inserts is shown in Fig. 10a and these tools with detailed parameters are performed in the experiments. The PCD tool with a cutting edge radius of $3.4279 \mu \mathrm{m}$ and a nose radius of $1.2 \mathrm{~mm}$ is measured by scanning electronic microscope (SEM). The rake angle and clearance angle for the inserts are both $0^{\circ}$, while the whole tooling system shown in Fig.

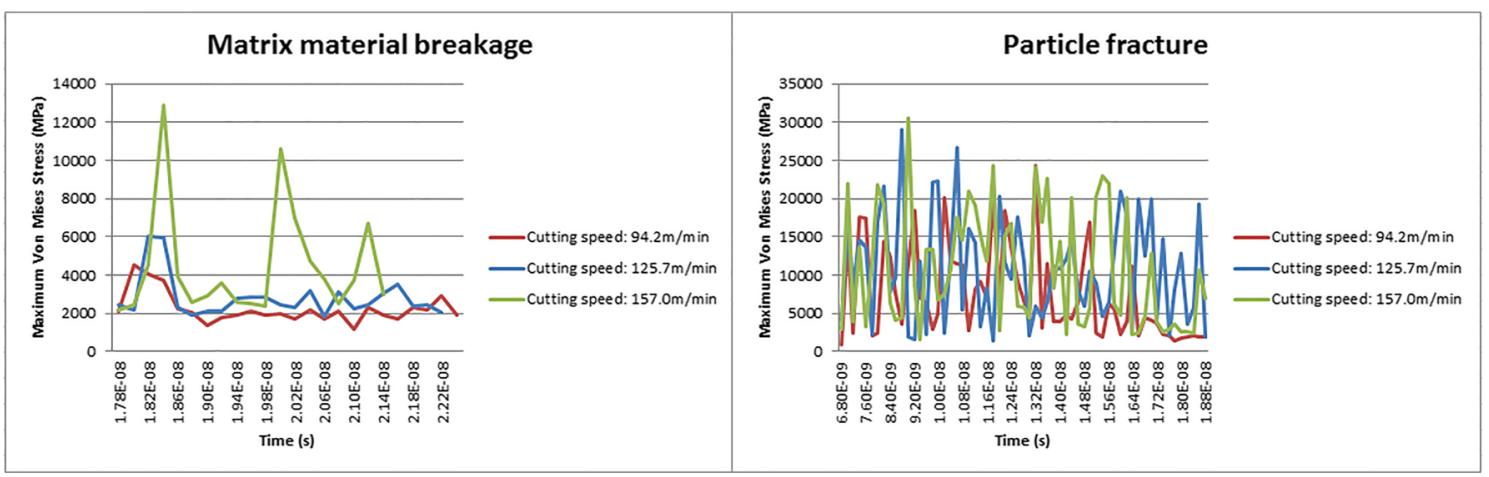

Fig. 7 Influence of the cutting speed on cutting stress 


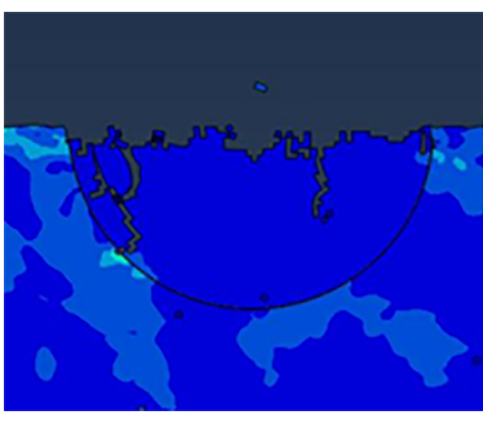

(a) DOC: $1 \mu \mathrm{m}$

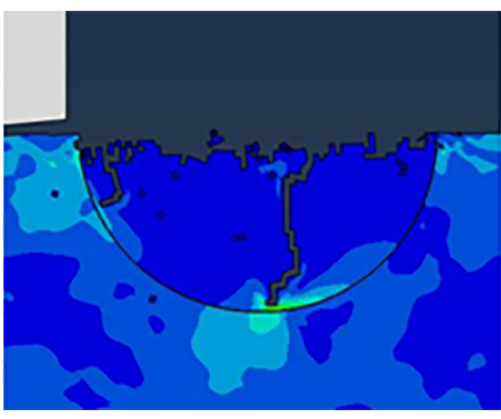

(b) DOC: $2.5 \mu \mathrm{m}$

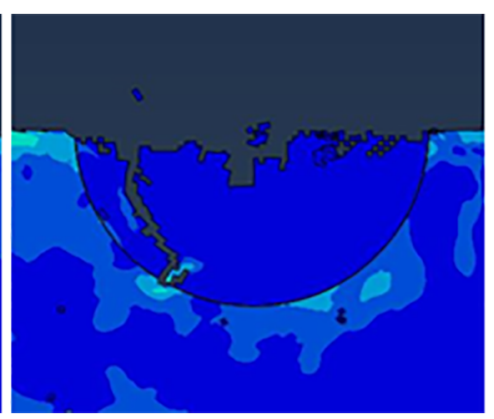

(c) DOC: $4 \mu \mathrm{m}$

Fig. 8 Influence of depth of cut on the machined surface performance. a DOC $1 \mu \mathrm{m}$. b DOC $2.5 \mu \mathrm{m}$. c DOC $4 \mu \mathrm{m}$

$10 \mathrm{~b}$ has a $5^{\circ}$ negative rake angle and $5^{\circ}$ clearance angle due to the geometry of tool holder. Experiments are performed on the basal plane of cylindrical $\mathrm{Al} 2024 / 50 \mathrm{~B}_{4} \mathrm{C}_{\mathrm{p}}$ workpiece with a diameter of $50 \mathrm{~mm}$ under various cutting conditions. The average grain size of particle is $5 \mu \mathrm{m}$ and volume fraction is $50 \%$. The cylinder workpiece is chunked on the spindle and tooling system is mounted on the work-plate slide. The entire experimental set-up is shown in Fig. 10 b.

\subsection{Experimental procedures}

The adopted cutting parameters in the experimental approach are shown in Table 6, which are configured the same as those utilized in simulations. These are used to perform the experimental cutting trials on their effects on the machined surface roughness. The cutting trials are conducted at various cutting parameters. In addition, only one of them is varied while the others are holding constant in order to observe the effects of input parameters. The achieved experimental results are assumed to compare with the simulation results. All the experimental trails are conducted under dry cutting condition, only air below is applied. The machined surface roughness, surface profile and topographical features are measured by ZYGO New View 5000 white light interferometer with excellent precision and accuracy.

\subsection{Results, analysis and discussion}

Table 7 illustrates the orthogonal array of cutting parameters in the experiments and resultant surface roughness at varied cutting conditions. 3D arithmetic mean roughness is applied for the surface roughness measurement in order to better illustrate the performance of machined surfaces. From Table 7, it can be clearly observed that surface roughness value decrease with the decrease of feed rate when the actual feed rate is larger than minimum chip thickness. In addition, the surface roughness has a significant decrease when cutting with larger cutting speed. Moreover, the best surface finish represented by the smallest surface roughness can be achieved when the depth of cut has the similar value with the radius of particles. The effects of these cutting parameters on surface integrity are illustrated in details in the following parts.

Figures 11 and 12 illustrate the resultant surface roughness at varied depth of cut (DOC). When the actual DOC is larger than the minimum chip thickness (MCT) of machining MMCs material, chips start to form. The machined surface roughness decreases slightly until DOC reaches to the value that similar to the reinforced particle radius. This is due to the pre-machining process that significantly affects the microstructure of MMCs in real cutting process. With continue steady increase of DOC, the surface roughness increase significantly. With the further increases of DOC, the force, stress friction and temperature increase. Then, the deposition of workpiece material results in higher surface roughness. In addition, when cutting with larger DOC, the stress generated on the matrix material may exceed the matrix-particle bonding stress. As a result, the reinforced particles will be much easier de-bonding and pulled out from the matrix material during precision machining. The higher strain at un-cut area means the particles are preferred removing together with the matrix material instead of being cut through. These result in the large amounts of pits and cracks on the remained surface. Thus, the best surface quality can be achieved when the depth of cut is close to the radius of reinforced particles. This states a good agreement with the simulation results in the scenario of the particle centre is located on the cutting line.

The 3D surface roughness and texture at varied feed rate are shown in Figs. 13 and 14, respectively. It can be observed that the surface roughness increase with the increase of feed rate and tool marks are becoming more significant. This can be illustrated as shown in Fig. 14. The remained peaks are higher when cutting with larger feed rate and surface roughness is then become larger. This is perfectly matched with the simulation results.

The surface roughness and surface profile along the tool path and tool mark are also demonstrated in Fig. 15. From the 2D surface profile, it can be seen that larger cracks and defects area occur when cutting with a smaller cutting speed. The 
Fig. 9 Surface performance vs feed rate. a Feed rate $10 \mu \mathrm{m} / \mathrm{rev}$. b Feed rate $20 \mu \mathrm{m} / \mathrm{rev}$. c Feed rate $30 \mu \mathrm{m} / \mathrm{rev}$
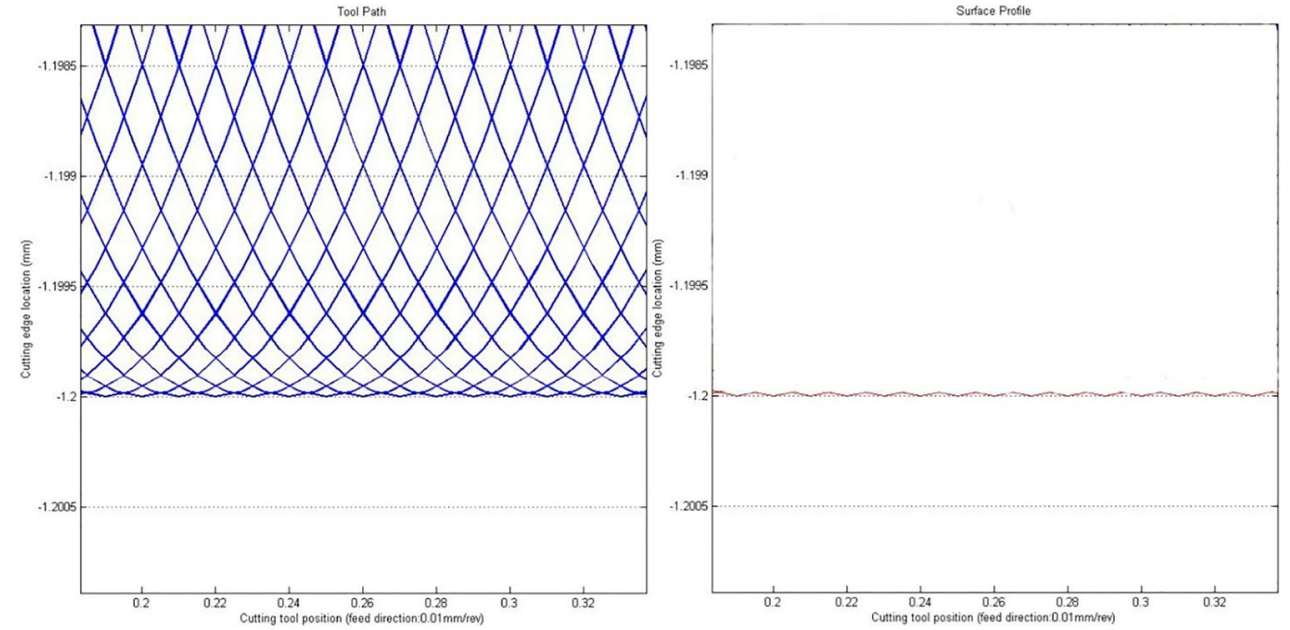

(a) Feed rate: $10 \mu \mathrm{m} / \mathrm{rev}$

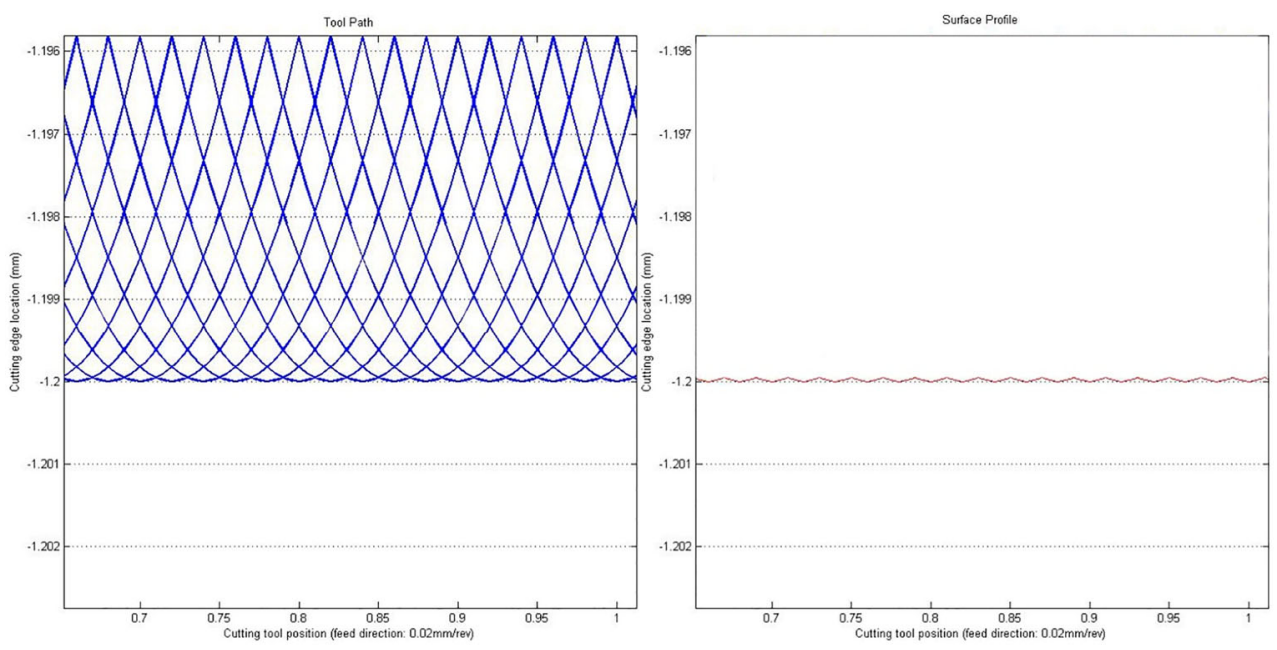

(b) Feed rate: $20 \mu \mathrm{m} / \mathrm{rev}$
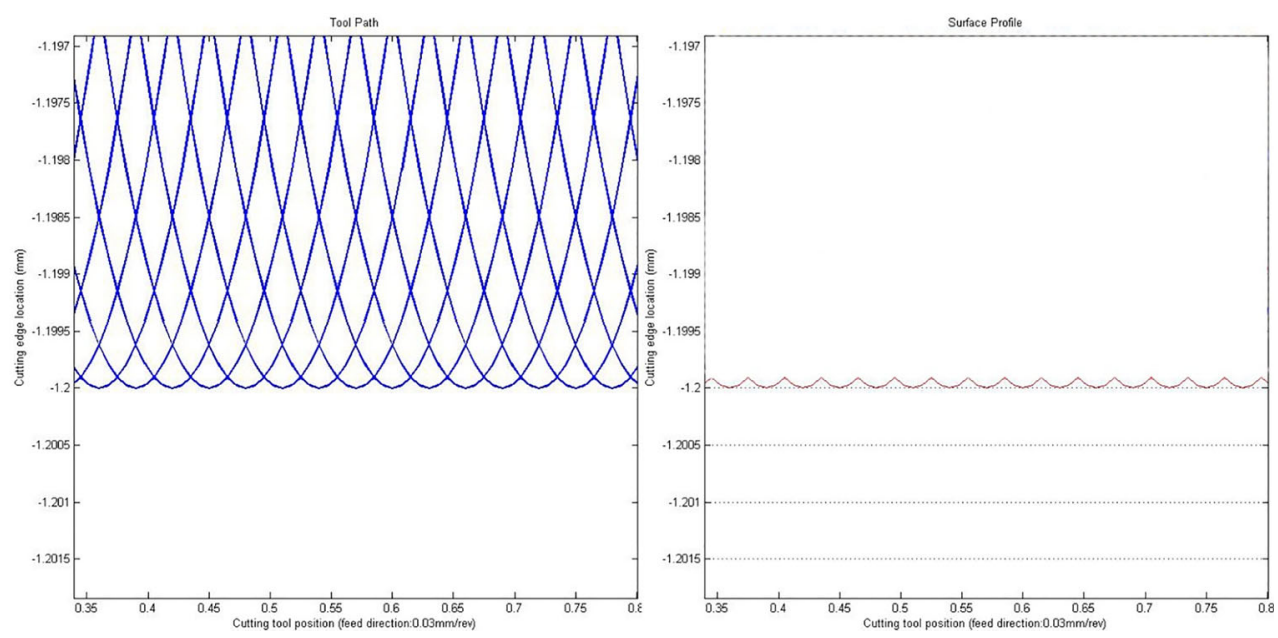

(c) Feed rate: $30 \mu \mathrm{m} / \mathrm{rev}$

large cavity area is significant; this can be attributed to the particles are pulled out or even fracture on the matrix material which leads to various particles are removed together and leave a large cavity. While, the larger cracks and defects will 
Table 5 Surface roughness and peak-to-valley value

\begin{tabular}{lll}
\hline Feed rate $(\mu \mathrm{m} / \mathrm{rev})$ & Peak-to-valley value $(\mathrm{nm})$ & $\mathrm{Ra}(\mathrm{nm})$ \\
\hline 10 & 10.417 & 2.671 \\
20 & 41.667 & 10.684 \\
30 & 93.754 & 24.083 \\
\hline
\end{tabular}

be replaced by small ones when increase the cutting speed. In addition, large cavities will be replaced by few cracks due to the brittle fracture occurs on particles rather than matrix material breakage or particles pulled out as shown in the figures of surface profile. The machined surface becomes smoother and surface quality is higher when cutting with a larger cutting speed. Figure 16 shows that less cracks and cavities are generated along the cutting direction when machining with higher cutting speed. The detailed surface profile illustrates the surface roughness decreases with the increase of cutting speed. This can be assumed that the particles are performed as perfectly cut through rather than pull out and leave smaller cracks or cavities at higher cutting speed. This is highly agreed with the simulation results in MMCs precision machining.
Table 6 Cutting parameters used in microturning experiments

\begin{tabular}{ll}
\hline Spindle speed (RPM) & $1000 / 800 / 600$ \\
\hline Cutting speed $(\mathrm{m} / \mathrm{min})$ & $157.0 / 125.7 / 94.2$ \\
Depth of cut $(\mu \mathrm{m})$ & $1 / 2.5 / 4$ \\
Feed rate $(\mu \mathrm{m} / \mathrm{rev})$ & $10 / 20 / 30$ \\
\hline
\end{tabular}

Tool marks and surface waviness can be significantly observed on the machined surface as shown in the measurement results. This can be attributed to the existence of the microhard particles. With the cutting tool shearing through the soft aluminium matrix and engaged on the hard particles, the suddenly increased stress and force result in the tool variation at the bonding interface. This increases the waviness and leave tool marks on the remained surface. These surface waviness and tool signature marks will increase the deviations in the direction of the normal vector of the machined surface from its ideal form. As a result, they increase the resultant surface roughness. During cutting on hard particles, the alternative stress change leads to the cutting tool variation. Cutting tool keeps rubbing on the machined surface and leaves more pits
Fig. 10 Experimental set-up for ultraprecision machining of MMCs. (a) The schematic of PCD inserts; (b) Experimental set-up

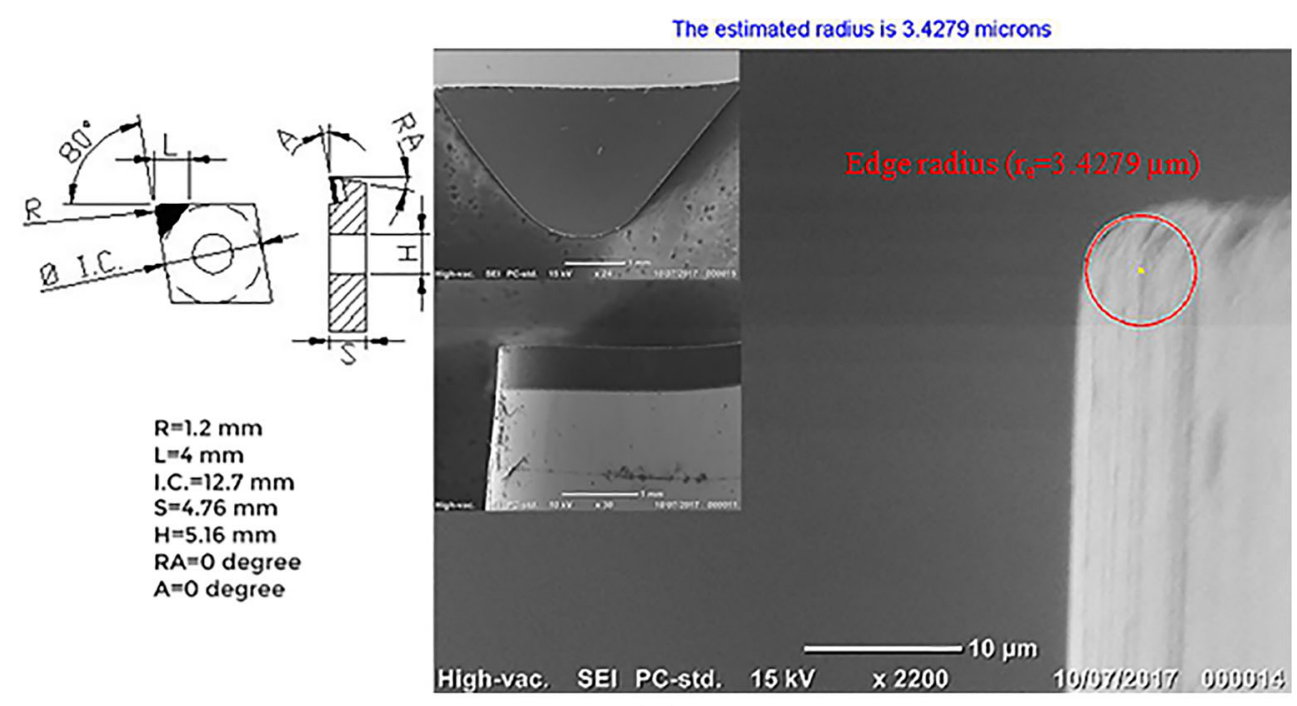

(a)

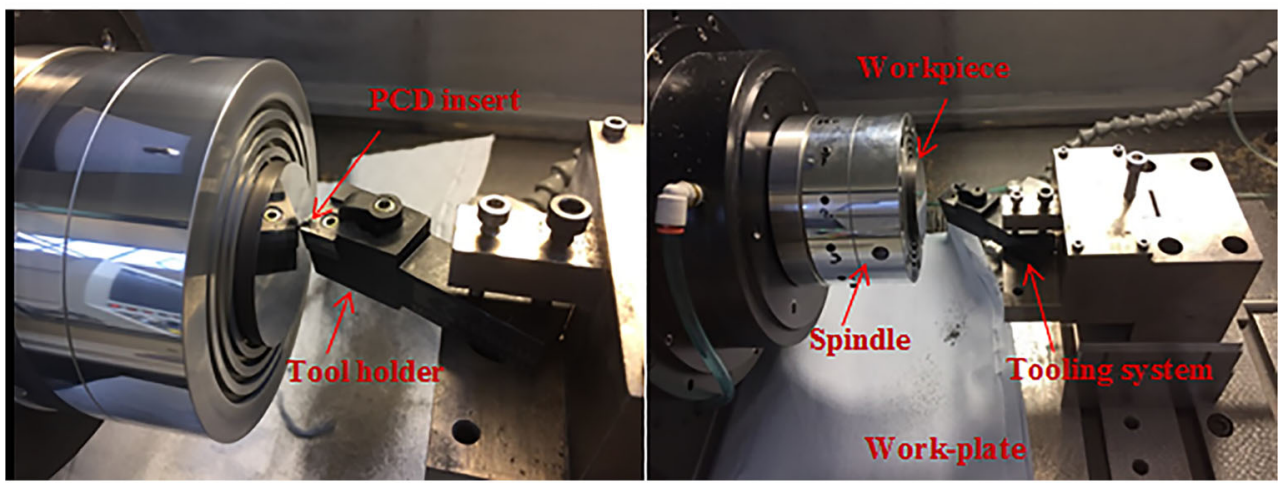

(b) 
Table 7 Orthogonal array of cutting parameters and resultant surface roughness

\begin{tabular}{|c|c|c|c|c|}
\hline $\begin{array}{l}\text { Experimental } \\
\text { number }\end{array}$ & $\begin{array}{l}\text { Cutting speed } \\
(\mathrm{m} / \mathrm{min})\end{array}$ & $\begin{array}{l}\text { Feed rate } \\
(\mu \mathrm{m} / \mathrm{rev})\end{array}$ & $\begin{array}{l}\text { Depth of cut } \\
(\mu \mathrm{m})\end{array}$ & $\begin{array}{l}\text { Surface } \\
\text { roughness } \\
(\mathrm{nm})\end{array}$ \\
\hline 1 & 157.0 & 30 & 4 & 132 \\
\hline 2 & 157.0 & 30 & 2.5 & 102 \\
\hline 3 & 157.0 & 30 & 1 & 105 \\
\hline 4 & 157.0 & 20 & 4 & 126 \\
\hline 5 & 157.0 & 20 & 2.5 & 99 \\
\hline 6 & 157.0 & 20 & 1 & 90 \\
\hline 7 & 157.0 & 10 & 4 & 90 \\
\hline 8 & 157.0 & 10 & 2.5 & 71 \\
\hline 9 & 157.0 & 10 & 1 & 86 \\
\hline 10 & 125.7 & 30 & 4 & 136 \\
\hline 11 & 125.7 & 30 & 2.5 & 134 \\
\hline 12 & 125.7 & 30 & 1 & 106 \\
\hline 13 & 125.7 & 20 & 4 & 135 \\
\hline 14 & 125.7 & 20 & 2.5 & 109 \\
\hline 15 & 125.7 & 20 & 1 & 113 \\
\hline 16 & 125.7 & 10 & 4 & 97 \\
\hline 17 & 125.7 & 10 & 2.5 & 90 \\
\hline 18 & 125.7 & 10 & 1 & 99 \\
\hline 19 & 94.2 & 30 & 4 & 148 \\
\hline 20 & 94.2 & 30 & 2.5 & 135 \\
\hline 21 & 94.2 & 30 & 1 & 136 \\
\hline 22 & 94.2 & 20 & 4 & 132 \\
\hline 23 & 94.2 & 20 & 2.5 & 117 \\
\hline 24 & 94.2 & 20 & 1 & 136 \\
\hline 25 & 94.2 & 10 & 4 & 113 \\
\hline 26 & 94.2 & 10 & 2.5 & 99 \\
\hline 27 & 94.2 & 10 & 1 & 129 \\
\hline
\end{tabular}
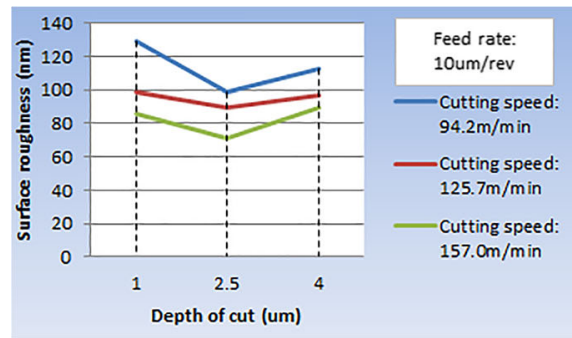

Fig. 11 Surface roughness vs depth of cut

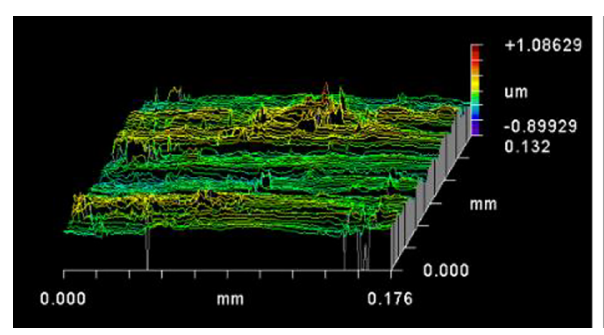

(a) DOC: $1 \mu \mathrm{m}$

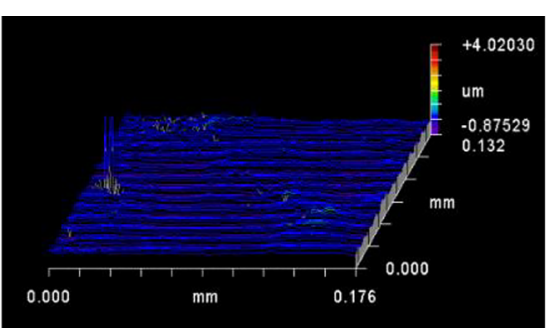

(b) DOC: $2.5 \mu \mathrm{m}$

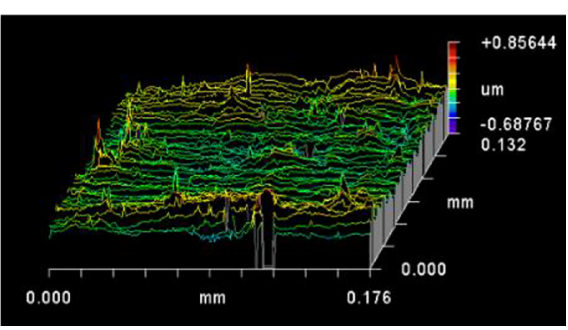

(c) DOC: $4 \mu \mathrm{m}$

Fig. 12 Surface roughness at varied DOC (cutting speed $125.7 \mathrm{~m} / \mathrm{min}$, feed rate $10 \mu \mathrm{m} / \mathrm{rev}$ ). a DOC $1 \mu \mathrm{m}$. b DOC $2.5 \mu \mathrm{m}$. c DOC $4 \mu \mathrm{m}$ 

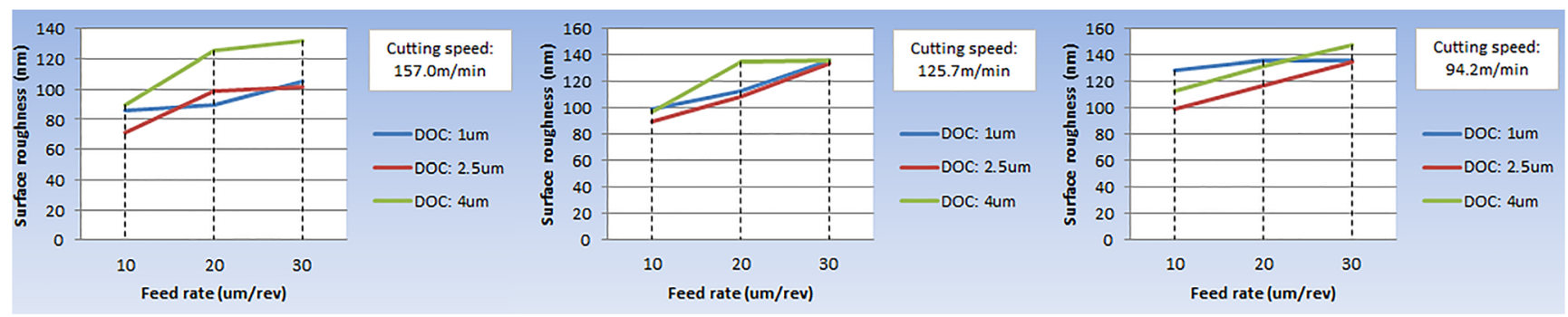

Fig. 13 Surface roughness vs feed rate

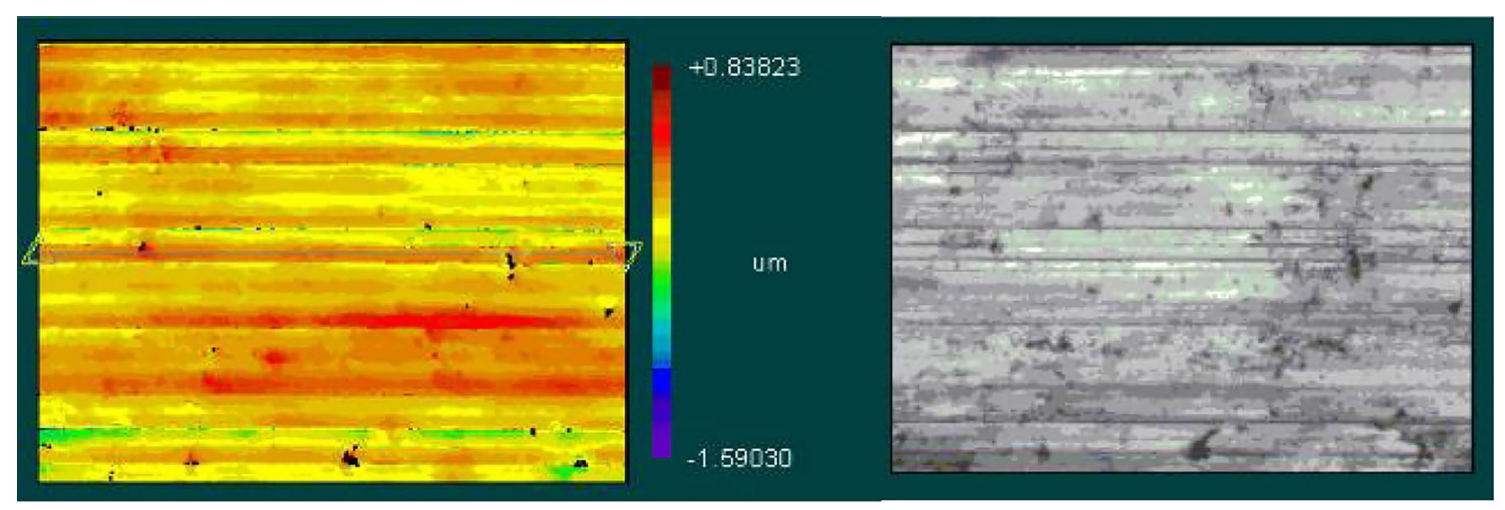

(a) Feed rate: $10 \mu \mathrm{m} / \mathrm{rev}$

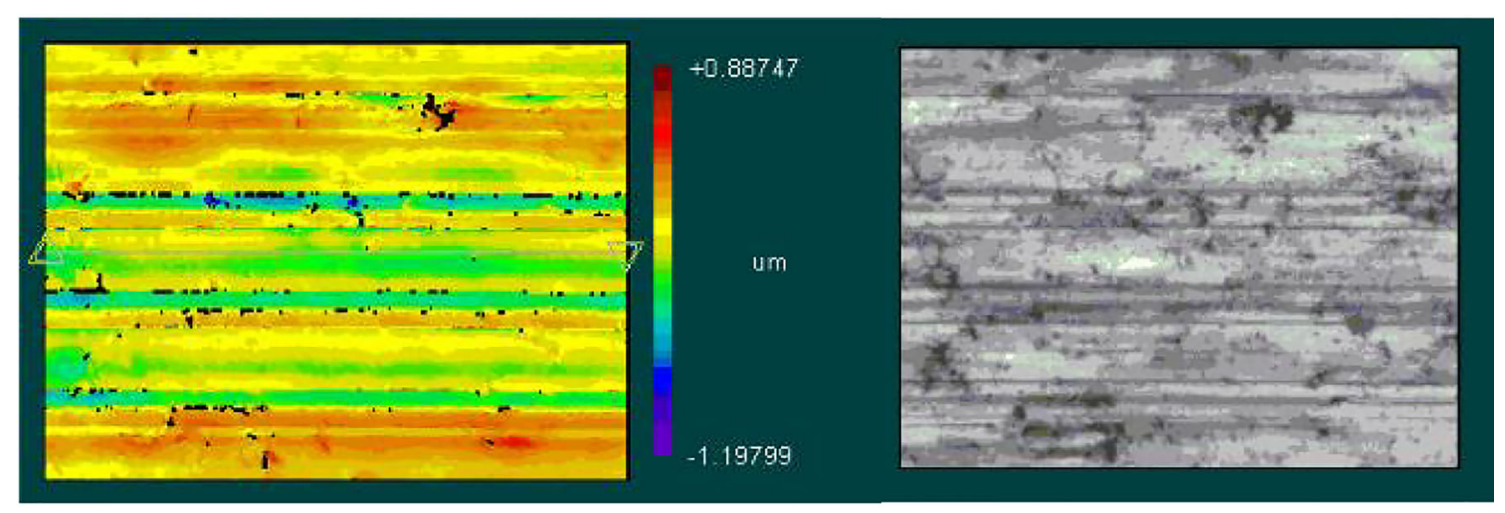

(b) Feed rate: $20 \mu \mathrm{m} / \mathrm{rev}$

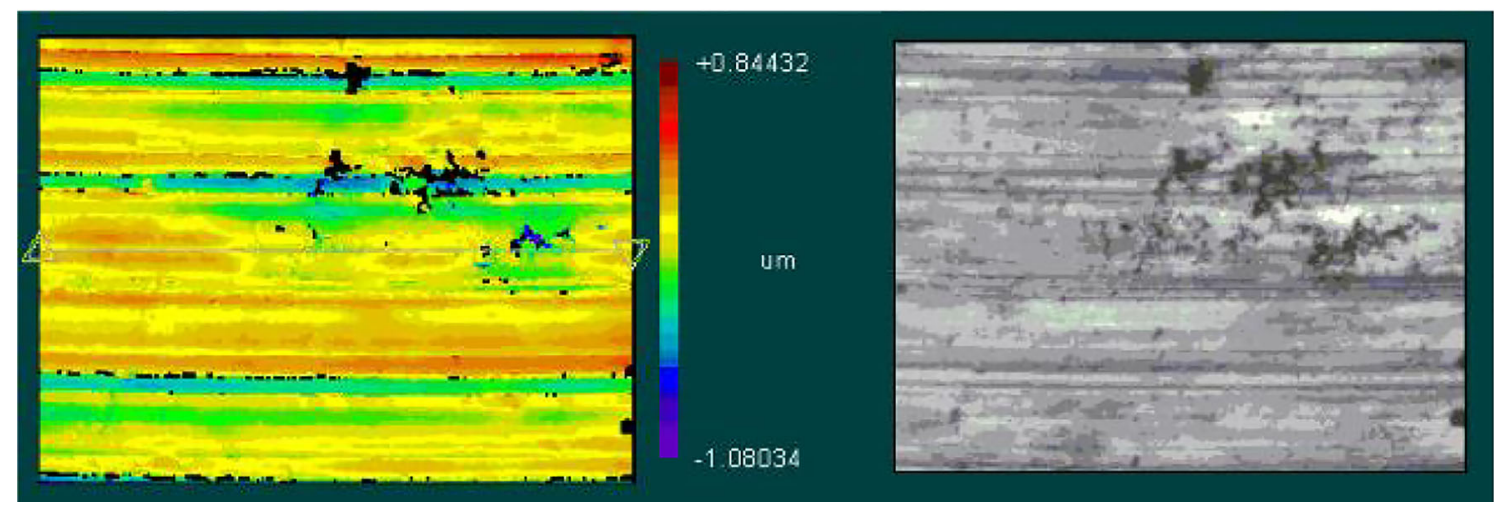

(c) Feed rate: $30 \mu \mathrm{m} / \mathrm{rev}$

Fig. 14 Surface roughness at varied feed rate (cutting speed $94.2 \mathrm{~m} / \mathrm{min}$, DOC $4 \mu \mathrm{m}$ ). a Feed rate $10 \mu \mathrm{m} / \mathrm{rev}$. b Feed rate $20 \mu \mathrm{m} / \mathrm{rev}$. c Feed rate $30 \mu \mathrm{m} / \mathrm{rev}$ 


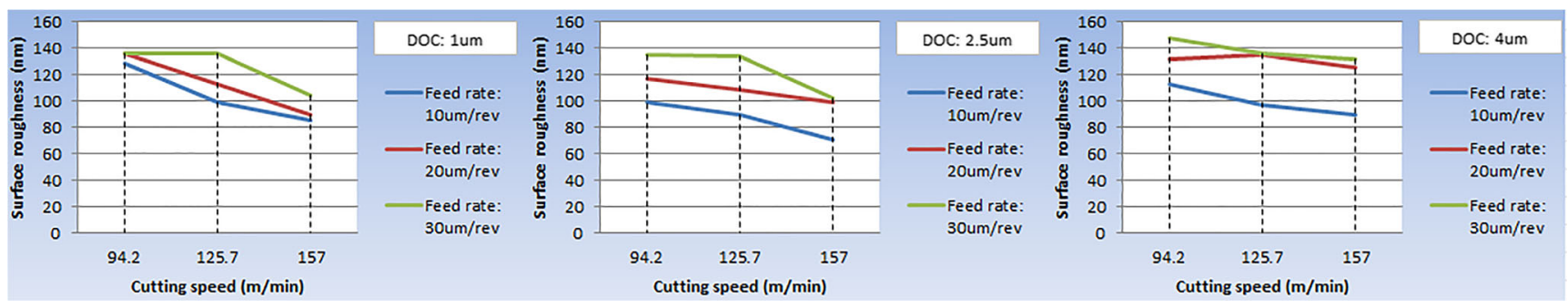

Fig. 15 Surface roughness vs cutting speed

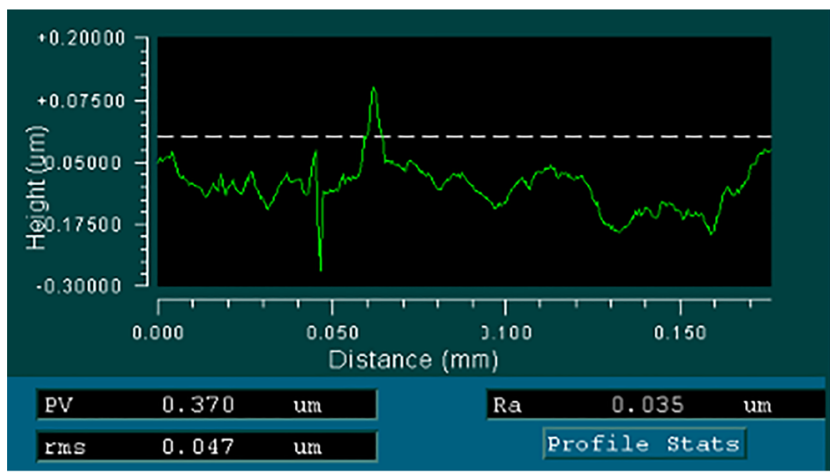

(a) Cutting speed: $157.0 \mathrm{~m} / \mathrm{min}$

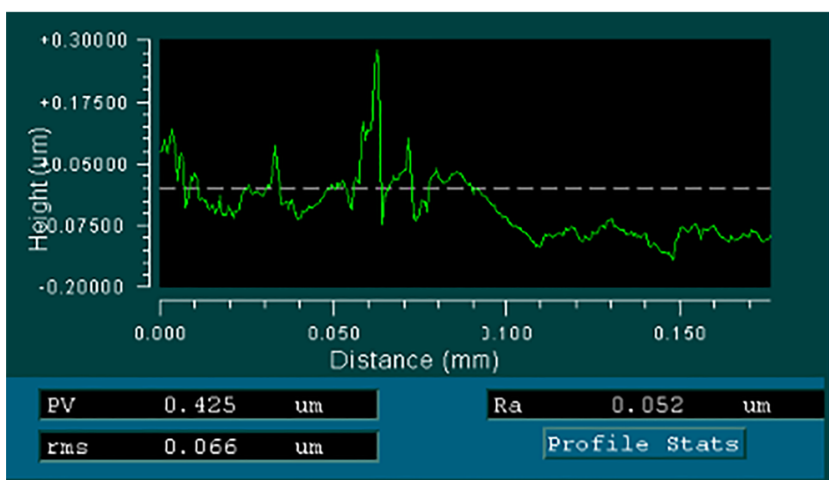

(b) Cutting speed: $125.7 \mathrm{~m} / \mathrm{min}$

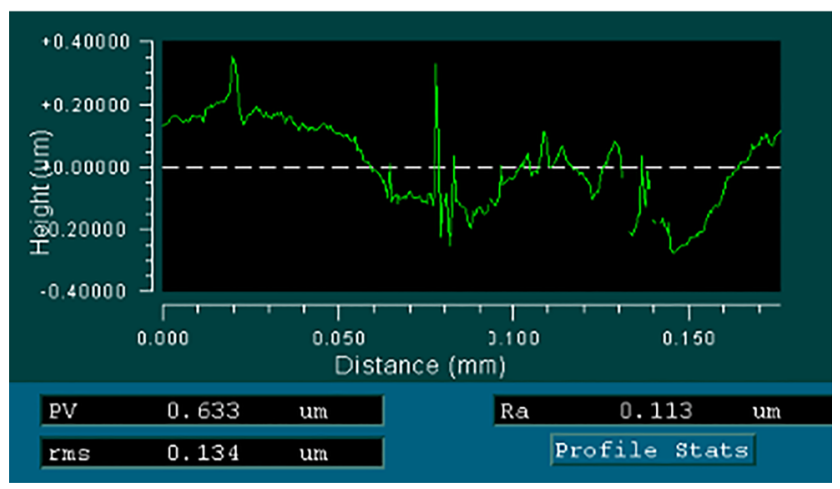

(c) Cutting speed: $94.2 \mathrm{~m} / \mathrm{min}$

Fig. 16 Surface roughness at varied cutting speed (feed rate $10 \mu \mathrm{m} / \mathrm{rev}$, DOC $1 \mu \mathrm{m}$ ). a Cutting speed $157.0 \mathrm{~m} / \mathrm{min}$. b Cutting speed $125.7 \mathrm{~m} / \mathrm{min}$. c Cutting speed $94.2 \mathrm{~m} / \mathrm{min}$ and cracks on the particles. After the tool cutting through the hard particles and engaged into the soft aluminium matrix, stress and force on the cutting tool are suddenly released. The stress of this high stiffness machining system suddenly relax and leads to the waviness of cutting tool which leaves significant tool marks and surface waviness and reduces the surface quality. Therefore, the surface roughness and surface defects at the machined particle-matrix bonding areas on the cutting line are larger than any other surface areas including the machined particle surface and matrix material surface. In addition, due to the high-volume fraction of reinforced particles, the stress changes alternatively. The resultant fluctuation of the cutting force increases the vibration in the cutting system also reduces the surface quality and the machining form accuracy. The dislocation and cracking of particles and also the interface de-bonding will damage the subsurface of MMCs which results in the reduction of the surface integrity. Therefore, the selection of optimal process variables is of great importance to achieve better surface quality in MMCs ultraprecision machining [31], which is consistent with the research results in ultraprecision and micromachining of other difficult-to-machine engineering materials [32].

\section{Conclusions}

An integrated simulation-experiment approach to ultraprecision machining of MMCs is presented, which aims to develop the comprehensive scientific understanding of the process mechanics and the consequent process optimization strategy, and furthermore the new protocol for the MMC material design and fabrication with much improved material machinability. The detailed conclusions can be drawn as follows:

1. Chip formation mechanics in ultraprecision machining of particle reinforced MMCs include the matrix breakage and particle fracture depending on the location of particles against the position of cutting tool tip. Plastic and elastic deformation at the matrix material occurs and chips are generated along the cutting line accompanied with the matrix/particle interfacial boundary de-bonding in these three scenarios. 
2. Three machining scenarios are presented to illustrate the material removal mechanics in precision machining of MMCs. In the first scenario of the particle centre located below the cutting line, small cracks are formed on the machined particles. Almost all of the cracks are generated towards lower direction of the un-machined particle area when cutting through the particles. Cavities, particularly at the particle/matrix interfacial area, can be observed, while more cracks can be observed at the tool approaching out area. In the second scenario of the particle centre located on the cutting line, cracks are generated towards cutting direction of the un-machined particles. This indicates that the particles break along the cutting line with fewer cracks formed on the tool path and finally leads to a much smoother surface generated with few defects. In the third scenario of the particle centre located over the cutting line, small cracks are formed on the machined particles. Cracks are generated towards both upper and lower directions of the un-machined particle area during machining. The cavities, particularly at the particle/matrix interfacial area, can be found. In addition, more cracks occur at the approaching in side of fractured particles.

3. Simulation results reveal that cutting speed, feed rate and depth of cut are the critical factors affecting the material removal and resultant surface roughness. Higher surface quality can be achieved by ultraprecision machining with higher cutting speed, smaller feed rate and appropriate small depth of cut.

4. The well-designed machining trials for evaluating and validating the simulation results and the approach indicate that the optimal cutting parameters for precision machining of MMCs are the higher cutting speed, DOC close to the reinforced particle radius and the appropriate lower feed rate. These perform a good agreement with simulation results. The process optimization and the associated optimization strategy are of great importance to obtain a higher machinability of MMCs.

Acknowledgements The authors thank Professor G.H. Wu and his team at Harbin Institute of Technology and Prima Tooling in providing the MMC materials and PCD tools for machining trials, and interesting and helpful discussion on the MMC materials design and fabrication.

Open Access This article is distributed under the terms of the Creative Commons Attribution 4.0 International License (http:// creativecommons.org/licenses/by/4.0/), which permits unrestricted use, distribution, and reproduction in any medium, provided you give appropriate credit to the original author(s) and the source, provide a link to the Creative Commons license, and indicate if changes were made.

\section{References}

1. Xavior MA, Kumar JPA (2017) Machinability of hybrid metal matrix composite - a review. Procedia Eng 174:1110-1118
2. Shorowordi KM, Laoui T, Haseeb ASMA, Celis JP, Froyen L (2003) Microstructure and interface characteristics of $\mathrm{B}_{4} \mathrm{C}, \mathrm{SiC}$ and $\mathrm{Al}_{2} \mathrm{O}_{3}$ reinforced $\mathrm{Al}$ matrix composites: a comparative study. J Mater Process Technol 142(3):738-743

3. Ibrahim MF, Ammar HR, Samuel AM, Soliman MS, Almajid A, Samuel FH (2014) Mechanical properties and fracture of Al-15 vol.-\%B4C based metal matrix composites. Int J Cast Met Res 27(1):7-14

4. Teti R (2002) Machining of composite materials. CIRP Ann 51(2): 611-634

5. Tomac N, Tannessen K, Rasch FO (1992) Machinability of particulate aluminium matrix composites. CIRP Ann 41(1):55-58

6. Balazinski M, Songmene V, Kishawy HA (2012) Analyzing the machinability of metal matrix composites. Mach Technol Compos Mater:394-411

7. Dandekar CR, Shin YC (2012) Modeling of machining of composite materials: a review. Int J Mach Tools Manuf 57:102-121

8. Pramanik A, Zhang LC, Arsecularatne JA (2007) An FEM investigation into the behavior of metal matrix composites: tool-particle interaction during orthogonal cutting. Int $\mathrm{J}$ Mach Tools Manuf 47(10):1497-1506

9. Zhou L, Huang ST, Wang D, Yu XL (2011) Finite element and experimental studies of the cutting process of $\mathrm{SiCp} / \mathrm{Al}$ composites with PCD tools. Int J Adv Manuf Technol 52(5-8):619-626

10. Shao JC, Xiao BL, Wang QZ, Ma ZY, Yang K (2011) An enhanced fem model for particle size dependent flow strengthening and interface damage in particle reinforced metal matrix composites. Compos Sci Technol 71(1):39-45

11. Ghandehariun A, Kishawy HA, Umer U, Hussein HM (2016) Analysis of tool-particle interactions during cutting process of metal matrix composites. Int J Adv Manuf Technol 82(1-4):143-152

12. Karabulut S, Karakoç H, Çıtak R (2016) Influence of $\mathrm{B}_{4} \mathrm{C}$ particle reinforcement on mechanical and machining properties of Al6061/ $\mathrm{B}_{4} \mathrm{C}$ composites. Compos Part B 101:87-98

13. Muthukrishnan N, Davim JP (2009) Optimization of machining parameters of $\mathrm{Al} / \mathrm{SiC}-\mathrm{MMC}$ with ANOVA and ANN analysis. $\mathrm{J}$ Mater Process Technol 209(1):225-232

14. Boswell B, Islam MN, Davies IJ, Pramanik A (2017) Effect of machining parameters on the surface finish of a metal matrix composite under dry cutting conditions. Proc Inst Mech Eng B J Eng Manuf 231(6):913-923

15. Manna A, Bhattacharyya B (2004) Investigation for optimal parametric combination for achieving better surface finish during turning of Al/SiC-MMC. Int J Adv Manuf Technol 23(9-10):658-665

16. Wang T, Xie LJ, Wang XB, Jiao L, Shen JW, Xu H, Nie FM (2013) Surface integrity of high speed milling of $\mathrm{Al} / \mathrm{SiC} / 65 \mathrm{p}$ aluminum matrix composites. Procedia CIRP 8:475-480

17. Babu TSM, Sugin MSA, Muthukrishnan N (2012) Investigation on the characteristics of surface quality on machining of hybrid metal matrix composite (Al-SiC-B4C). Procedia Eng 38:2617-2624

18. Kumaran ST, Uthayakumar M, Slota A, Aravindan S, Zajac J (2016) Machining behavior of AA6351-SiC-B4C hybrid composites fabricated by stir casting method. Part Sci Technol 34(5):586592

19. Chan KC, Cheung CF, Ramesh MV, Lee WB, To S (2001) A theoretical and experimental investigation of surface generation in diamond turning of an Al6061/SiCp metal matrix composite. Int J Mech Sci 43(9):2047-2068

20. Liu J, Li J, Xu C (2014) Interaction of the cutting tools and the ceramic-reinforced metal matrix composites during micro-machining: a review. CIRP J Manuf Sci Technol 7(2):55-70

21. Fathipour M, Hamedi M, Yousefi R (2013) Numerical and experimental analysis of machining of $\mathrm{Al}(20 \mathrm{vol} \% \mathrm{SiC})$ composite by the use of ABAQUS software. Mater Sci Eng 44(1):14-20

22. Kumar R, Chauhan S (2015) Study on surface roughness measurement for turning of $\mathrm{Al} 7075 / 10 / \mathrm{SiCp}$ and Al 7075 hybrid 
composites by using response surface methodology (RSM) and artificial neural networking (ANN). Measurement 65:166-180

23. Ding X, Liew WYH, Liu XD (2005) Evaluation of machining performance of MMC with PCBN and PCD tools. Wear 259(712): $1225-1234$

24. Hibbitt, Kaarlsson, Sorensen (2001) ABAQUS/Explicit user's manual. Hibbitt, Karlsson and Sorensen Incorporated

25. Zhang H, Ramesh K, Chin E (2005) Effects of interfacial debonding on the rate-dependent response of metal matrix composites. Acta Mater 53(17):4687-4700

26. Kan Y, Liu ZG, Zhang SH, Zhang LW, Cheng M, Song HW (2014) Microstructure-based numerical simulation of the tensile behavior of $\mathrm{SiCp} / \mathrm{Al}$ composites. J Mater Eng Perform 23(3):1069-1076

27. Niu Z, Cheng K (2016) Multiscale multiphysics-based modeling and analysis on the tool wear in micro drilling. J Multisc Model $7(1): 1-22$

28. Wang T, Xie L, Wang X (2015) Simulation study on defect formation mechanism of the machined surface in milling of high volume fraction SiCp/Al composite. Int J Adv Manuf Technol 79(5-8): $1185-1194$

29. Niu Z, Jiao F, Cheng K (2018) An innovative investigation on chip formation mechanisms in micro-milling using natural diamond and tungsten carbide tools. J Manuf Process 31(1):382-394

30. Abdullah AB, Chia LY, Samad Z (2008) The effect of feed rate and cutting speed to surface roughness. Asian J Sci Res 1:12-21

31. Niu Z, Cheng K (2019) An experimental investigation on surface generation in ultraprecision machining of particle reinforced metal matrix composites. Int J Adv Manuf Technol:1-9. https://doi.org/ 10.1007/s00170-018-03256-y

32. Cheng K, Huo DH (2013) Micro cutting: fundamentals and applications. John Wiley \& Sons, Chichester

Publisher's note Springer Nature remains neutral with regard to jurisdictional claims in published maps and institutional affiliations. 